\section{(2) OPEN ACCESS}

\title{
Educational differences in the influence of health on early work exit among older workers
}

\author{
Sascha De Breij ำ, ${ }^{1}$ Jana Mäcken, ${ }^{2}$ Jeevitha Yogachandiran Qvist, ${ }^{3}$ \\ Daniel Holman (ㄱ, , ${ }^{4}$ Moritz Hess, ${ }^{5}$ Martijn Huisman, ${ }^{1,6}$ Dorly J H Deeg ${ }^{1}$
}

'Epidemiology and Biostatistics, Amsterdam UMC - Locatie VUMC, Amsterdam, The Netherlands

${ }^{2}$ Institute of Sociology and Social Psychology, University of Cologne, Koln, Germany ${ }^{3}$ Centre for Comparative Welfare Studies, Department of Politics and Society, Aalborg University, Aalborg, Denmark

${ }^{4}$ Department of Sociological Studies, University of Sheffield, Sheffield, UK

${ }^{5}$ Research Center on Inequality and Social Policy, University of Bremen, Bremen, Germany ${ }^{6}$ Department of Sociology, VU University Amsterdam, Amsterdam, The Netherlands

\section{Correspondence to}

Ms Sascha De Breii,

Epidemiology and Biostatistics, Amsterdam UMC - Locatie VUMC, 1081 HV Amsterdam, The Netherlands:

s.debreij@amsterdamumc.nl

Received 9 October 2019 Revised 11 March 2020 Accepted 20 March 2020 Published Online First 8 April 2020

\section{ABSTRACT \\ Objectives Previous research has shown that poor} physical and mental health are important risk factors for early work exit. We examined potential differences in this association in older workers (50+) across educational levels.

Methods Coordinated analyses were carried out in longitudinal data sets from four European countries: the Netherlands (Longitudinal Aging Study Amsterdam), Denmark (Danish Longitudinal Study of Ageing), England (English Longitudinal Study of Ageing) and Germany (German Ageing Survey). The effect of poor self-rated health (SRH), functional limitations and depression on different types of early work exit (early retirement, economic inactivity, disability and unemployment) was examined using Cox regression analysis. We examined educational differences in these effects by testing interaction terms.

Results Poor physical and mental health were more common among the lower educated. Poor SRH,

functional limitations, and depression were all associated with a higher risk of early work exit. These health effects were strongest for the disability exit routes (poor SRH: HRs 5.77 to 8.14; functional limitations: HRs 6.65 to 10.42; depression: HRs 3.30 to 5.56). In the Netherlands (functional limitations) and England (functional limitations and SRH), effects were stronger in the lower educated.

Conclusions The prevalence of health problems, that is, poor SRH, functional limitations and depression, was higher in the lower educated workers. All three health indicators increase the risk of early work exit. In some countries, health effects on early exit were stronger in the lower educated. Thus, lower educated older workers are an important target group for health policy and intervention.

\section{INTRODUCTION}

To address the economic challenge stemming from population ageing ${ }^{1}$ and ensure the sustainability of social security systems, many countries are encouraging older workers to delay retirement by raising the statutory retirement age and closing early retirement options. However, prolonging working lives may be challenging, especially for workers with low levels of education. Several mechanisms through which poor health influences early work exit have been identified in qualitative studies. First, some workers feel unable to work at all or perceive a decline in (future) workability due to health problems. ${ }^{2} 3$ Second,

\section{Key messages}

What is already known about this subject?

- Poor health is associated with early work exit. Early work exit and poor health are more common among lower educated workers.

What are the new findings?

- Poor self-rated health, functional limitations and depression were risk factors for early work exit, especially for disability pension. Educational differences were found in the effects of poor self-rated health and functional limitations, with stronger effects in the lower educated workers, in England and the Netherlands.

How might this impact on policy or clinical practice in the foreseeable future?

- Because poor health is more common and health effects on early work exit may be stronger among lower educated workers, targeting this specific group in health policy and interventions may be successful in decreasing the rate of early work exit.

some workers express fear that their health would decline even further if they continue working and choose instead to exit the workforce to preserve their health. Third, workers with poor health may feel pushed out by their employer. ${ }^{2}$

Low education has been shown to be associated with on average more physical ${ }^{4-6}$ and mental health problems ${ }^{7-9}$ as well as lower life expectancy. ${ }^{10}$ Because poor health is a main determinant of work exit, ${ }^{11-14}$ social inequalities in health may result in unequal opportunities to extend working lives. Empirical evidence suggests that people with low levels of education tend to exit the workforce earlier. ${ }^{15-17}$ Research on the differential influence of health on early work exit across educational levels is limited and results are inconsistent. Some studies concluded that the association between poor health and work exit is stronger in the lower educated, ${ }^{18} 19$ while others found opposite results, with stronger health effects in higher educated workers, ${ }^{20}$ or no educational differences. ${ }^{21}$ These studies differed in the countries examined and in their measures of health and work exit.

On the one hand, compared with lower educated workers, higher educated workers tend to have lower physical work demands, ${ }^{22}$ a stronger 
attachment to work, ${ }^{23}$ are more able to make changes to their work environment, ${ }^{23}$ and have a higher sense of control, ${ }^{24}$ meaning that they will be on average better positioned to continue working, even with health limitations. Therefore, it might be that poor health affects early work exit more strongly in those with low compared with those with high levels of education. On the other hand, higher educated workers may be more inclined to retire early to preserve their health ${ }^{2}$ and are more able to do so financially than lower educated workers.

Despite solid evidence linking poor health to early work exit, previous research has several limitations. Most studies have not examined the modifying roles of educational level and have focussed on either physical or mental health, offering an incomplete understanding of how different aspects of health influence early work exit across workers with different educational levels. ${ }^{12} 2325$

In the current study, we investigate how different health indicators affect early work exit in low and highly educated older workers in four countries.

\section{METHODS}

EXTEND is a cross-national collaborative project which aims to examine inequalities in relation to extending working lives. In this study we included data sets from the four participating countries in this project: the Netherlands, Denmark, England and Germany. These countries were included in the EXTEND project because they all have a strong focus on closing early retirement options and have high levels of employment among older workers. By adopting a coordinated analysis approach, the aim was to maximise generalisability. ${ }^{26}$ As such, by doing the exact same analyses in each data set and using similar variables, differences between countries are likely due to differences at the country level and not differences in methodology. If results are consistent across countries, there is evidence for generalisability to different national settings.

\section{Sample}

For the Dutch sample, data come from the Longitudinal Aging Study Amsterdam (LASA). ${ }^{27}$ LASA is a nationwide ongoing longitudinal study in people aged $55+$, with follow-ups every 3 years. Data from the first (respondents aged 55 to 84 entering the study in 1992 to 1993), second (new respondents aged 55 to 64 entering the study in 2002 to 2003) and third (new respondents aged 55 to 64 entering the study in 2012 to 2013) cohorts were pooled for the current study $(\mathrm{n}=1295)$ and all waves through 2016 were included.

Denmark is represented by the Danish Longitudinal Study of Ageing (DLSA), which is merged with Danish register data on labour market exit. The study focusses on people aged $52+$ and consists of four consecutive waves with 5 years between each wave (1997, 2002, 2007 and 2012) and with respondents born in the years between 1920 and $1960 .{ }^{28}$ Starting from 2002 a new cohort was added at each new wave. In the current study data from all waves $(n=4721)$ were used.

The English data come from the English Longitudinal Study of Ageing (ELSA), a study of a large representative sample of men and women aged $50+{ }^{29}$ The study began in 2002 and the sample is re-examined every 2 years. For the current study, data from waves 1 through 7 were used $(n=4508)$.

The German data come from the German Ageing Survey (DEAS), a longitudinal survey of the German population aged $40+$, which started in $1996 .{ }^{30}$ Further waves followed in 2002, 2008, 2011 and 2014, with new cohorts added every 6 years.
Data from four waves since 2002 were used in this study $(\mathrm{n}=1203)$. Wave 1 (1996) was excluded because data on functional limitations were not available. For this study we included respondents aged 50 years and older to maximise cross-country comparability.

In all data sets respondents entered our analysis at the first wave in which they reported having paid work and were followed up to 15 years. This could be the baseline measurement or a follow-up measurement, on whichever the respondent reported having paid work for the first time in the study. Further inclusion criteria were being at least 50 years old, being younger than the statutory retirement age and having at least one follow-up measurement after reporting having paid work.

\section{Measures}

\section{Dependent variable}

The dependent variable was early work exit, defined as having no paid work after reporting having paid work at the previous wave and not having yet reached the statutory retirement age. In all studies, work exit was self-reported and could have different reasons: early retirement, disability, unemployment or economic inactivity (those leaving the labour market but not receiving income or benefits, for example, homemakers). In Denmark data on the economic inactivity route were not available.

\section{Independent variables \\ Educational level}

The International Standard Classification of Education 2011 (ISCED 2011) was used to categorise educational level into three groups: low (up to lower secondary education, ISCED 0 to 2), intermediate (upper secondary education or post-secondary nontertiary education, ISCED 3 to 4 ) and high (short cycle tertiary and higher, ISCED 5 to 6 ).

\section{Self-rated health}

Self-rated health (SRH) was measured with the question 'How is your health in general?' with response options on a 5-point Likert scale. Responses were dichotomised into good/excellent SRH and less than good SRH.

\section{Functional limitations}

Data on functional limitations were available in all data sets, but different measures were used. The Dutch study used six items: cutting one's own toenails, dressing and undressing oneself, sitting down and standing up from a chair, walking outside for 5 min without stopping, walking up and down a staircase of 15 steps without resting and use of own or public transportation. Five response options ranged from 'yes, without difficulty' to 'no, I cannot'.

In the Danish study functional limitations were measured using six items: walking around in one's house, cutting one's toenails, walking on stairs, taking clothes or shoes on and off, taking a shower/wash oneself and walking outside. Three response options ranged from 'able alone without difficulty' to 'no, I cannot'.

In the English study functional limitations were measured using five items: bathing, dressing, eating, getting in or out of bed and walking across a room. Respondents had a functional limitations score of 0 to 5 representing the number of activities they reported any difficulty with.

In the German study functional limitations were measured with the SF-36 scale. Ten items were included: moderate activities 
such as moving a table, climbing several flights of stairs, bending or kneeling, lifting and carrying groceries, walking more than one kilometre, walking several blocks, walking one block, eating meals and drinking liquids and bathing and dressing oneself, ${ }^{31}$ with three response options ranging from 'limited a lot' to 'not limited at all'.

All scores were dichotomised into having no functional limitations, that is, having mild difficulty or being somewhat limited with zero or one out of at least five items, and having functional limitations, that is, having difficulty or being somewhat limited with two or more items.

\section{Depression}

In the Dutch, English, and German studies, depressive symptoms were measured with the Centre for Epidemiologic Studies Depression Scale (CES-D). ${ }^{32}$ The scale consists of 20 items covering depressive symptomatology experienced in the past week. In the Netherlands the complete scale was used; in England (eight items) and Germany (15 items) shortened versions were used. There are four response options ranging from 0 'rarely or never' to 3 'mostly or always'. Higher scores indicate more depressive symptoms. The clinical cut-off scores used to indicate depression in each country were as follows: the Netherlands $\geq 16$, England $\geq 4$, Germany $\geq 12$. In Denmark, one item was used to measure depression: 'Did a doctor tell you that you have - or within the last year have had - a depression?'.

\section{Control variables}

We controlled for year, region (not available in Denmark), baseline age, partner status and the number of working hours. ${ }^{33}$ In Denmark and England, partner status was categorised as no partner/partner retired/partner not retired. In the Netherlands and Germany, partner status was categorised as partner/no partner, because no information on the retirement status of the partner was available. Number of working hours was categorised into four categories representing the most common part-time, full-time and more than full-time working hours in each country. In the Netherlands categories were: 1 to 15,16 to 31,32 to 40 , $\geq 41$; in Denmark: 1 to 28,29 to $36,37, \geq 38$; in England: 1 to 29,30 to 37,38 to $44, \geq 45$ and in Germany: 1 to 29,30 to 39 , 40 to $44, \geq 45$.

\section{Missing values}

If the percentage of missing values on the independent variables exceeded 5\%, we used multiple imputation, assuming missingness at random. All independent, control and outcome variables were included in the imputation process and the number of imputations was equal to the percentage of incomplete cases (table 1, first rows, last column). Imputed outcomes were deleted afterwards.

\section{Statistical analysis}

To examine the association between health and early work exit, we used Cox regression analyses, with age as the time-scale, accounting for clustering due to repeated measures and for delayed entry, that is, respondents enter the risk set at the age of study entry, given that they have reached that age without occurrence of the event. ${ }^{34}$ Those lost to follow-up without work exit or still working at the end of the study period were censored at their last available wave. Those reaching the statutory retirement age while still at work were censored at the statutory retirement age. We conducted cause-specific analyses in which in each model one of the exit routes was the event while the other exit routes were censored. Because of small sample sizes, we could not conduct cause-specific analyses including interaction terms between health and education in each country. These interactions were therefore tested in analyses with total early work exit as the outcome, that is, all exit routes taken together. We reported results for the total sample of workers in each country as well as results stratified by educational level. In case of a significant interaction $\left(\mathrm{p}<0.10^{35}\right)$, we conducted additional cause-specific analyses, if possible. If there was no statistical support for an interaction with education, education was included as a confounder. SRH, functional limitations, depression, partner status and number of working hours were included as time-varying covariates. Results are reported as HRs with 95\% CIs.

\section{RESULTS}

Characteristics of the samples can be found in table 1. A higher percentage of workers with less than good SRH and a higher percentage of depressed workers were found in Germany and England, compared with the Netherlands and Denmark. Functional limitations were most evident in the Netherlands and Germany. Early retirement was the most frequent exit route, followed by inactivity (unemployment in Denmark). Involuntary exit routes, that is, disability and unemployment, were more frequent among the lower educated.

Table 2 shows the associations between the health indicators and each exit route. Health effects were strongest for the disability exit route. All three health indicators substantially increased the risk of exiting the work force early through disability, in all countries. Health effects were also evident for the other exit routes, although less pronounced. The risk of unemployment was higher among workers with poor SRH compared with workers with good SRH. In Denmark and England, results also suggest an increased risk of unemployment among workers with functional limitations and depression. Functional limitations and depression were also associated with a higher risk of becoming economically inactive. Additionally, poor SRH, functional limitations and depression were associated with a higher risk of early retirement, except in the Netherlands.

In table 3, the associations between the three health indicators and total early work exit can be found, for the total sample as well as for each educational group separately. Statistically significant educational differences (in bold) were found in the Netherlands, Denmark and England. In England, poor $\mathrm{SRH}$ was a stronger risk factor in low (HR 1.66, 95\% CI 1.34 to 2.05 ) and intermediately (HR $1.47,95 \%$ CI 1.24 to 1.74) compared with highly (HR $1.18,95 \%$ CI 0.93 to 1.50 ) educated workers. Additional cause-specific analyses on the effect of poor SRH showed educational differences in the effect on early retirement, with a stronger effect in the low educated workers (HR 1.46, 95\% CI 1.06 to 2.02) compared with those with an intermediate (HR 1.11, 95\% CI 0.89 to 1.38 ) and high educational level (HR 1.05, 95\% CI 0.78 to 1.39). Furthermore, having functional limitations was a much stronger risk factor in English workers with a low (HR 2.67, 95\% CI 1.65 to 4.34 ) and intermediate (HR 3.00, 95\% CI 2.06 to 4.36) education compared with highly educated workers (HR $1.30,95 \%$ CI 0.46 to 3.66). The percentage of highly educated workers with functional limitations was too low to be able to conduct cause-specific analyses.

In the Netherlands, having functional limitations was a risk factor in the low educated workers only (HR 1.50, 95\% CI 1.08 
Table 1 Characteristics of the samples (at the last wave before work exit/censoring)

\begin{tabular}{|c|c|c|c|c|c|c|c|c|c|}
\hline Education & $\begin{array}{l}\text { Low early } \\
\text { exit }\end{array}$ & Censored & $\begin{array}{l}\text { Intermediate } \\
\text { early exit }\end{array}$ & Censored & $\begin{array}{l}\text { High early } \\
\text { exit }\end{array}$ & Censored & $\begin{array}{l}\text { Total early } \\
\text { exit }\end{array}$ & Censored & $\begin{array}{l}\% \text { missing } \\
\text { before MI }\end{array}$ \\
\hline \multicolumn{10}{|l|}{ Sample size (n) } \\
\hline The Netherlands & 221 & 354 & 100 & 206 & 122 & 292 & 443 & 852 & 0.4 \\
\hline Denmark & 429 & 335 & 1126 & 1172 & 644 & 1015 & 2199 & 2522 & 3.6 \\
\hline England & 349 & 1120 & 551 & 1584 & 296 & 608 & 1196 & 3312 & 8.5 \\
\hline Germany & 57 & 80 & 144 & 328 & 157 & 437 & 358 & 845 & 0.9 \\
\hline \multicolumn{10}{|l|}{ Male (\%) } \\
\hline The Netherlands & 53.3 & 55.7 & 56.7 & 58.1 & 64.9 & 64.6 & 57.2 & 59.3 & 0 \\
\hline Denmark & 40.3 & 55.8 & 51.6 & 59.1 & 43 & 54.4 & 46.9 & 56.8 & 0 \\
\hline England & 55 & 46 & 55.7 & 51.8 & 71 & 54.1 & 59.3 & 50.2 & 0 \\
\hline Germany & 31.6 & 38.8 & 48.4 & 47.3 & 48.4 & 54.2 & 45.3 & 50.1 & 0 \\
\hline \multicolumn{10}{|l|}{ Partner (\%) } \\
\hline The Netherlands & & & & & & & & & 0 \\
\hline No partner & 17.8 & 17.5 & 15.1 & 18 & 15.1 & 18.1 & 16.5 & 17.8 & \\
\hline Partner & 82.2 & 82.5 & 84.9 & 82 & 84.9 & 81.9 & 83.5 & 82.2 & \\
\hline Denmark & & & & & & & & & 2.5 \\
\hline No partner & 27 & 31.9 & 21.5 & 25.1 & 25.1 & 27.9 & 23.6 & 27.2 & \\
\hline Partner not retired & 44.8 & 45.4 & 47.6 & 55 & 45.1 & 53.2 & 46.3 & 53 & \\
\hline Partner retired & 28.2 & 22.7 & 30.9 & 19.9 & 29.8 & 18.9 & 30.1 & 19.9 & \\
\hline England & & & & & & & & & 5.1 \\
\hline No partner & 22.4 & 23.2 & 20.2 & 21 & 15.3 & 21 & 19.6 & 21.7 & \\
\hline Partner not retired & 8.4 & 6.6 & 5.6 & 6 & 7.1 & 5.8 & 6.8 & 6.2 & \\
\hline Partner retired & 69.2 & 70.2 & 74.3 & 73 & 77.6 & 73.2 & 73.6 & 72.1 & \\
\hline Germany & & & & & & & & & 0 \\
\hline No partner & 28.1 & 21.2 & 20.1 & 20.1 & 21.7 & 22 & 22.1 & 21.2 & \\
\hline Partner & 71.9 & 78.8 & 79.9 & 80.9 & 78.3 & 78 & 77.9 & 78.8 & \\
\hline \multicolumn{10}{|c|}{ Number of working hours (\%) } \\
\hline The Netherlands & & & & & & & & & 0.4 \\
\hline $1-15$ & 23.4 & 30.4 & 21.2 & 20.9 & 20.2 & 15.8 & 22 & 23.1 & \\
\hline $16-31$ & 29.9 & 26.1 & 18.2 & 37.4 & 31.9 & 28.4 & 27.3 & 29.6 & \\
\hline $32-40$ & 38.1 & 34.1 & 43.4 & 30.1 & 43.7 & 41.8 & 40.8 & 35.8 & \\
\hline$\geq 41$ & 9.6 & 9.4 & 17.2 & 11.6 & 4.2 & 14 & 9.9 & 11.5 & \\
\hline Denmark & & & & & & & & & 0.7 \\
\hline $1-28$ & 16.3 & 13.1 & 13.8 & 10.5 & 11.5 & 8.5 & 13.6 & 10 & \\
\hline $29-36$ & 15.6 & 10.8 & 15.8 & 11.5 & 13.2 & 9.5 & 15 & 10.6 & \\
\hline 37 & 48.7 & 43.6 & 50.5 & 46.5 & 48.3 & 42.2 & 49.5 & 44.4 & \\
\hline$\geq 38$ & 19.4 & 32.5 & 19.9 & 31.5 & 27 & 39.9 & 21.9 & 35 & \\
\hline England & & & & & & & & & 2.1 \\
\hline $1-29$ & 21.3 & 22.5 & 22.7 & 25.9 & 36.1 & 35.5 & 25.6 & 26.5 & \\
\hline $30-37$ & 31.8 & 27.7 & 26.2 & 18.9 & 17.6 & 18.3 & 25.7 & 21.8 & \\
\hline $38-44$ & 19.3 & 25.5 & 28 & 30.6 & 25.1 & 28.2 & 24.7 & 28.4 & \\
\hline$\geq 45$ & 27.7 & 24.4 & 23.1 & 24.6 & 21.2 & 18 & 24 & 23.3 & \\
\hline Germany & & & & & & & & & 0.2 \\
\hline $1-29$ & 33.3 & 25 & 27.8 & 21.7 & 24.2 & 14.9 & 27.1 & 18.4 & \\
\hline $30-39$ & 22.8 & 21.3 & 25 & 21.7 & 18.5 & 19.9 & 21.8 & 20.7 & \\
\hline $40-44$ & 31.6 & 32.5 & 30.6 & 32 & 31.9 & 28.6 & 31.3 & 30.3 & \\
\hline$\geq 45$ & 12.3 & 21.3 & 16.7 & 24.7 & 25.5 & 36.6 & 19.8 & 30.5 & \\
\hline \multicolumn{10}{|l|}{ Type of exit (\%) } \\
\hline The Netherlands & & & & & & & & & 0 \\
\hline Early retirement & 49.5 & & 49 & & 53.3 & & 50.5 & & \\
\hline Disability & 10.6 & & 9 & & 8.2 & & 9.6 & & \\
\hline Unemployment & 9.2 & & 13 & & 11.5 & & 10.7 & & \\
\hline Economic inactivity & 30.7 & & 29 & & 27.1 & & 29.3 & & \\
\hline Denmark & & & & & & & & & 0 \\
\hline Early retirement & 55.7 & & 60.7 & & 68.7 & & 69.9 & & \\
\hline Disability & 5.8 & & 6.2 & & 3.3 & & 5.3 & & \\
\hline Unemployment & 38.5 & & 33.1 & & 28 & & 24.8 & & \\
\hline
\end{tabular}


Table 1 continued

\begin{tabular}{|c|c|c|c|c|c|c|c|c|c|}
\hline Education & $\begin{array}{l}\text { Low early } \\
\text { exit }\end{array}$ & Censored & $\begin{array}{l}\text { Intermediate } \\
\text { early exit }\end{array}$ & Censored & $\begin{array}{l}\text { High early } \\
\text { exit }\end{array}$ & Censored & $\begin{array}{l}\text { Total early } \\
\text { exit }\end{array}$ & Censored & $\begin{array}{l}\% \text { missing } \\
\text { before } \mathrm{MI}\end{array}$ \\
\hline England & & & & & & & & & 0 \\
\hline Early retirement & 43 & & 59.7 & & 79.4 & & 59.7 & & \\
\hline Disability & 18.6 & & 10.9 & & 3.7 & & 11.4 & & \\
\hline Unemployment & 20.1 & & 14 & & 8.8 & & 14.5 & & \\
\hline Economic inactivity & 18.3 & & 15.4 & & 8.1 & & 14.5 & & \\
\hline Germany & & & & & & & & & 0 \\
\hline Early retirement & 36.8 & & 45.1 & & 52.2 & & 46.9 & & \\
\hline Disability & 12.3 & & 3.5 & & 7 & & 6.4 & & \\
\hline Unemployment & 21.1 & & 20.8 & & 12.7 & & 17.3 & & \\
\hline Economic inactivity & 29.8 & & 30.6 & & 28 & & 29.3 & & \\
\hline \multicolumn{10}{|l|}{ Less than good SRH (\%) } \\
\hline The Netherlands & 25.1 & 27.8 & 24.2 & 21.4 & 10.9 & 13.4 & 21.1 & 21.3 & 0 \\
\hline Denmark & 29.8 & 24.9 & 23.2 & 15.9 & 17.8 & 11 & 22.9 & 15.1 & 0.4 \\
\hline England & 56.4 & 47.1 & 46.1 & 37.3 & 28.4 & 29.6 & 44.7 & 39.2 & 0 \\
\hline Germany & 43.9 & 38.8 & 42.4 & 47.3 & 38.9 & 34.3 & 41.1 & 39.8 & 0.2 \\
\hline \multicolumn{10}{|c|}{ Functional limitations (\%) } \\
\hline The Netherlands & 16.4 & 12.2 & 14.1 & 16 & 3.4 & 5.8 & 12.4 & 10.9 & 0 \\
\hline Denmark & 2.3 & 2.7 & 3 & 1 & 2.2 & 1.2 & 2.7 & 1.3 & 0.5 \\
\hline England & 4.3 & 1.3 & 3.3 & 1.5 & 0.7 & 1 & 2.9 & 1.3 & 0 \\
\hline Germany & 28.1 & 21.3 & 23.6 & 26.8 & 23.6 & 16.5 & 24.3 & 21 & 0 \\
\hline \multicolumn{10}{|l|}{ Depression (\%) } \\
\hline The Netherlands & 10.1 & 8.2 & 7.1 & 3.9 & 6.7 & 5.8 & 8.5 & 6.4 & 0 \\
\hline Denmark & 7 & 2 & 5.6 & 2.2 & 6.7 & 3.8 & 6.3 & 2.3 & 0 \\
\hline England & 19.2 & 12.7 & 12.5 & 10.6 & 8.5 & 8.6 & 13.5 & 11 & 0 \\
\hline Germany & 19.3 & 11.3 & 16.7 & 14.6 & 15.9 & 9.8 & 16.8 & 11.8 & 0.6 \\
\hline
\end{tabular}

*Percentages reported in first rows (sample size) are percentages of incomplete cases.

$\mathrm{MI}$, multiple imputation; SRH, self-rated health.

to 2.09). Additional cause-specific analyses showed educational differences for the disability exit route only (low: HR 10.50, $95 \%$ CI 4.81 to 22.91 ; intermediate: HR $7.34,95 \%$ CI 1.59 to 33.95; high: HR 1.93, 95\% CI 0.22 to 17.24$)$.

In Denmark, the opposite effect was found. Functional limitations was a risk factor in intermediately and highly educated workers only. Cause-specific analyses showed educational differences only for the disability (low: HR 1.06, 95\% CI 0.13 to 8.53 ; intermediate: HR 13.01 , 95\% CI 5.72 to 29.6 ; high: HR 9.15, 95\% CI 2.79 to 30.02 ) and unemployment (low: HR $0.27,95 \%$ CI 0.04 to 1.96 ; intermediate: HR 2.89 , 95\% CI 1.66 to 5.03 ; high: HR $0.36,95 \%$ CI 0.05 to 2.57 ) route.

Table 2 Main effects of health on early retirement, economic inactivity, disability and unemployment

\begin{tabular}{|c|c|c|c|c|}
\hline & Early retirement $\mathrm{HR}^{\mathrm{b}}(95 \% \mathrm{Cl})$ & Economic inactivity $\mathrm{HR}^{\mathrm{b}}(95 \% \mathrm{Cl})$ & Disability $\mathrm{HR}^{\mathrm{b}}(95 \% \mathrm{Cl})$ & Unemployment $\mathrm{HR}^{\mathrm{b}}(95 \% \mathrm{Cl})$ \\
\hline \multicolumn{5}{|c|}{ Less than good SRH } \\
\hline The Netherlands & $0.86(0.59$ to 1.24$)$ & 1.01 (0.64 to 1.59$)$ & $5.86(3.05 \text { to } 11.25)^{* *}$ & $1.58(0.80$ to 3.10$)$ \\
\hline Denmark & $1.51(1.28 \text { to } 1.78)^{* *}$ & N/A & $8.14(5.33 \text { to } 12.44)^{* *}$ & $1.72(1.45 \text { to } 2.04)^{* *}$ \\
\hline England & $1.15(1.00$ to 1.34$) \dagger$ & $1.14(0.82$ to 1.59$)$ & $5.77(3.75 \text { to } 8.90)^{* *}$ & $1.72(1.27 \text { to } 2.33)^{* *}$ \\
\hline Germany & $1.08(0.79$ to 1.47$)$ & $1.15(0.78$ to 1.70$)$ & $N / A^{c}$ & $1.46(0.90$ to 2.38$)$ \\
\hline \multicolumn{5}{|c|}{ Functional limitations } \\
\hline The Netherlands & $0.70(0.41$ to 1.21$)$ & 1.15 (0.71 to 1.88$)$ & $7.30(4.03 \text { to } 13.22)^{* *}$ & $1.01(0.41$ to 2.50$)$ \\
\hline Denmark & $1.08(0.62$ to 1.88$)$ & $\mathrm{N} / \mathrm{A}$ & $6.65(3.54 \text { to } 12.51)^{* *}$ & $1.32(0.79$ to 2.21$)$ \\
\hline England & $1.49(0.93$ to 2.40$) \dagger$ & $2.28(1.06 \text { to } 4.89)^{*}$ & $10.42(6.48 \text { to } 16.75)^{* *}$ & 1.59 (0.65 to 3.94$)$ \\
\hline Germany & $1.29(0.94$ to 1.77$)$ & $1.57(1.03 \text { to } 2.38)^{*}$ & $N / A^{c}$ & 0.88 (0.47 to 1.64$)$ \\
\hline \multicolumn{5}{|l|}{ Depression } \\
\hline The Netherlands & $0.82(0.43$ to 1.59$)$ & $1.70(0.95$ to 3.03$) \dagger$ & $5.56(2.67 \text { to } 11.60)^{* *}$ & $0.93(0.28$ to 3.07$)$ \\
\hline Denmark & $1.49(1.10 \text { to } 2.03)^{*}$ & $\mathrm{~N} / \mathrm{A}$ & $3.33(1.84 \text { to } 6.05)^{* *}$ & $2.30(1.75 \text { to } 3.04)^{* *}$ \\
\hline England & 1.12 (0.87 to 1.44$)$ & $1.73(1.15 \text { to } 2.60)^{* *}$ & $3.30(2.25 \text { to } 4.84)^{* *}$ & $1.58(1.05 \text { to } 2.38)^{*}$ \\
\hline Germany & $1.26(0.79$ to 2.01$)$ & $1.77(1.06 \text { to } 2.98)^{*}$ & $N / A^{c}$ & $0.72(0.30$ to 1.71$)$ \\
\hline
\end{tabular}

$\mathrm{tp} \leq 0.10 ;{ }^{*} \mathrm{p} \leq 0.05 ;{ }^{* *} \mathrm{p} \leq 0.01 .{ }^{b} \mathrm{HR}$ adjusted for education, sex, age at study entry, year, partner status, number of working hours and region.

${ }^{c}$ Case number $(n=23)$ too low.

$\mathrm{SRH}$, self-rated health. 
Table 3 HRs for early work exit by educational level

\begin{tabular}{|c|c|c|c|c|}
\hline & Netherlands & Denmark & England & Germany \\
\hline & $\mathrm{HR}^{\mathrm{d}}(95 \% \mathrm{Cl})$ & $\mathrm{HR}^{\mathrm{d}}(95 \% \mathrm{Cl})$ & $\mathrm{HR}^{\mathrm{d}}(95 \% \mathrm{Cl})$ & $H^{d}{ }^{d}(95 \% C l)$ \\
\hline Less than good SRH & $1.23(0.97$ to 1.55$) \dagger$ & $1.90(1.68 \text { to } 2.14)^{* *}$ & $1.44(1.28 \text { to } 1.63)^{* *}$ & $1.17(0.98$ to 1.41$) \dagger$ \\
\hline Low education & 1.09 (0.81 to 1.46$)$ & $1.93(1.52 \text { to } 2.46)^{* *}$ & $1.66(1.34 \text { to } 2.05)^{* *}$ & 1.12 (0.71 to 1.78$)$ \\
\hline Intermediate education & $1.56(0.97$ to 2.50$) \dagger$ & $1.91(1.62 \text { to } 2.25)^{* *}$ & $1.47(1.24 \text { to } 1.74)^{* *}$ & 1.06 (0.80 to 1.41$)$ \\
\hline High education & 1.34 (0.77 to 2.33 ) & $1.97(1.53 \text { to } 2.53)^{* *}$ & $1.18(0.93$ to 1.50$)$ & 1.32 (0.99 to 1.75$) \dagger$ \\
\hline Functional limitations & 1.24 (0.95 to 1.65$)$ & $1.67(1.19 \text { to } 2.34)^{* *}$ & $2.58(1.91 \text { to } 3.50)^{* *}$ & $\begin{array}{l}1.43(1.18 \text { to } \\
1.75)^{* *}\end{array}$ \\
\hline Low education & $1.50(1.08 \text { to } 2.09)^{*}$ & 0.76 (0.31 to 1.86$)$ & $2.67(1.65 \text { to } 4.34)^{* *}$ & 1.44 (0.90 to 2.30$)$ \\
\hline Intermediate education & 1.27 (0.72 to 2.25$)$ & $2.42(1.56 \text { to } 3.74)^{* *}$ & $3.00(2.06 \text { to } 4.36)^{* *}$ & $1.38(1.02 \text { to } 1.86)^{*}$ \\
\hline High education & 0.51 (0.19 to 1.40$)$ & 1.74 (0.89 to 3.42$)$ & 1.30 (0.46 to 3.66$)$ & $1.49(1.08 \text { to } 2.05)^{*}$ \\
\hline Depression & $1.77(1.37 \text { to } 2.29)^{* *}$ & $2.10(1.71 \text { to } 2.58)^{* *}$ & $1.54(1.29 \text { to } 1.83)^{* *}$ & $\begin{array}{l}1.54(1.18 \text { to } \\
2.00)^{* *}\end{array}$ \\
\hline Low education & 1.41 (0.93 to 2.12 ) & $1.75(1.14 \text { to } 2.68)^{*}$ & $1.57(1.19 \text { to } 2.07)^{* *}$ & $1.64(0.94$ to 2.87$) \dagger$ \\
\hline Intermediate education & 1.72 (0.76 to 3.89$)$ & $2.05(1.49 \text { to } 2.81)^{* *}$ & $1.40(1.09 \text { to } 1.80)^{* *}$ & 1.26 (0.84 to 1.88$)$ \\
\hline High education & $1.82(1.00 \text { to } 3.31)^{*}$ & $2.79(1.93 \text { to } 4.05)^{* *}$ & $1.70(1.17 \text { to } 2.47)^{* *}$ & $\begin{array}{l}1.97(1.31 \text { to } \\
2.96)^{* *}\end{array}$ \\
\hline
\end{tabular}

$\mathrm{tp} \leq .10 ;{ }^{*} \mathrm{p} \leq .05 ;{ }^{* *} \mathrm{p} \leq .01 .{ }^{\mathrm{d}} \mathrm{HR}$ adjusted for age at study entry, sex, year, partner status, number of working hours and region. HRs in bold indicate a significant interaction $(p<.10)$ between health and education (ref.cat=low).

$\mathrm{SRH}$, self-rated health.

\section{DISCUSSION}

The aim of this study was to examine the role of SRH, functional limitations and depression as risk factors for early work exit among older workers across educational levels.

Low educated workers more often had poor SRH, functional limitations and a depression compared with higher educated workers. This was evident in all four participating countries. All three health indicators were associated with early work exit. Health effects were strongest for the disability exit route, supporting findings of earlier research. ${ }^{12}$ Poor physical and mental health also increased the risk of early retirement, economic inactivity and unemployment. However, country differences were found in these associations. In the Netherlands, poor health was not associated with a higher risk of early retirement. The Dutch early retirement schemes used to be relatively flexible and generous compared with the other countries, especially before the reforms in 2006. ${ }^{36}$ Therefore, Dutch workers who were still in good health may also have chosen to retire early to preserve their good health, ${ }^{2}$ without making a large financial sacrifice for their extended time in retirement.

In Germany and the Netherlands, functional limitations and depression were not associated with a higher risk of unemployment, while we did find these associations in Denmark and England. This may be because in Germany and the Netherlands, employment protection legislation is stricter than in Denmark and England, ${ }^{35}$ making it harder for firms to make workers redundant, for example because of their health problems.

In the Netherlands and England, the effect of functional limitations on early work exit was stronger in low and intermediately educated workers than in highly educated workers. This corresponds to our expectation that functional limitations cause difficulty performing the type of work that lower educated workers generally do and that in such cases they qualify for disability benefits sooner. Indeed, the cause-specific models in the Dutch data show that these educational differences were found only for the disability exit route. In the English data set, such analyses were not possible, due to the very low number of workers with functional limitations. In England, we also found that poor SRH was a stronger risk factor for early retirement in low compared with higher educated workers. It may be that low educated workers in poor $\mathrm{SRH}$, who were not eligible for disability pension but also not able to continue working, chose to retire early. However, further research on motives of early retirement is necessary to clarify these findings.

In Denmark, functional limitations was a risk factor for disability and unemployment among workers with an intermediate and high educational level only. This lack of effect in the low educated Danish workers is likely due to the healthy worker effect, ${ }^{37}$ that is, workers with functional limitations may have already left the workforce prior to entering our study, especially the lower educated workers, who more often have physically demanding jobs. Indeed, the number of Danish workers with functional limitations was very low and we did not find the usual educational gradient for functional limitations. Those still working with functional limitations may have less severe limitations, or may have jobs that accommodate their health problems better.

In contrast to the majority of existing research on determinants of early work exit which has paid limited attention to educational differences and tended to focus on a single health indicator, we conducted coordinated analyses in four longitudinal data sets to maximise generalisability of our findings across different national contexts and focussed on the modifying effect of educational level. We also included mental and physical health indicators as possible risk factors. Our study shows that results for one health indicator cannot necessarily be transferred to another and that the modifying effect of education differs between countries.

Our study has some limitations. Because all data sets included older workers only, the effects of health on early work exit may be underestimated due to the healthy worker effect. ${ }^{37}$ Furthermore, the main effects of health on disability pension could not be examined in Germany due to the low number of disability exits. Also, we could not examine educational differences in all cause-specific models, because of the low number of events in some of the educational strata and the low number of unhealthy cases in some countries. Further research should therefore make use of larger data sets to replicate our results and differentiate between the various exit routes, to explore the educational differences more in-depth. So far, in most studies on the relation 
between health and early work exit, education has been treated as a confounder. Our findings, however, highlight the importance of taking into account the possible modifying effect of education in studies regarding health and early work exit.

The data sets used in our study differ in the age range of the participants as well as in the follow-up time. This may affect the results. However, because we used a coordinated analysis approach and thus conducted identical analyses and used measurements as similar as possible, country differences are less likely due to differences in the study design, but rather to actual country differences in factors at the individual, company and/ or state level. ${ }^{26}$ The country differences found in the modifying role of education may give insight into other factors contributing to inequalities in early work exit. These contextual factors may explain the inconsistency of results from previous studies investigating the modifying role of socioeconomic position in the relation between health and work exit. ${ }^{17-20}$

Poor SRH, functional limitations and depression were risk factors for early exit from paid work in all four countries. These effects were strongest for the disability exit route. These health problems increase with age. With retirement ages rising, it is important to implement policies to improve health in older workers to prevent early work exit as well as to facilitate working by making tailored adjustments for workers with health problems. Not only are health problems more common among the lower educated, in some countries the effects of health on early work exit are also stronger in this group of workers. Therefore, lower educated older workers are an important target group for health policy and intervention.

\section{Twitter Daniel Holman @danjholman}

Acknowledgements The authors would like to acknowledge the EXTEND partners for providing feedback on the study.

Contributors All authors made substantial contributions to conception and design of the study. SDB (LASA), JYQ (DLSA), DH (ELSA), and JM (DEAS) conducted the statistical analyses. SDB interpreted the data and drafted the methods, results, discussion and conclusion. JM drafted the introduction. All authors revised the manuscript critically. All authors read and approved the final manuscript.

Funding The research was conducted within the project 'EXTEND: Social inequalities in extending working lives of an ageing workforce' in the framework of the Joint Programming Initiative (JPI) 'More Years, Better Lives - The Potential and Challenges of Demographic Change'. SDB was supported by The Netherlands Organisation for Health Research and Development (ZonMW) (grant number 208 060 002). DH was supported by the Economic and Social Research Council (grant number ES/P000177/1).

Competing interests None declared.

Patient consent for publication Not required.

Ethics approval EXTEND conducts secondary analyses on the data collected within the participating cohort studies. All participating cohort studies have originally received consent of the participants and ethical approval from their respected institutions.

Provenance and peer review Not commissioned; externally peer reviewed.

Data availability statement Data are available in a public, open access repository. Data are available upon reasonable request. Data may be obtained from a third party and are not publicly available. Data from the Longitudinal Aging Study Amsterdam (LASA; www.lasa-vu.nl) are available for use for specific research questions provided that an agreement is made up. Data from the English Longitudinal Study of Ageing (ELSA) are available from the UK Data Archive (http:// data-archive.ac.uk/). Data from the Danish Longitudinal Study of Ageing (DLSA) are available from the Centre for Survey and Survey/Register data (CSSR) (http:// cssr.surveybank.aau.dk/webview/). Data from the German Aging Study (DEAS) are available from the German Centre of Gerontology (https://www.dza.de/en/fdz/ german-ageing-survey/access-to-deas-data.html).

Open access This is an open access article distributed in accordance with the Creative Commons Attribution Non Commercial (CC BY-NC 4.0) license, which permits others to distribute, remix, adapt, build upon this work non-commercially, and license their derivative works on different terms, provided the original work is properly cited, appropriate credit is given, any changes made indicated, and the use is non-commercial. See: http://creativecommons.org/licenses/by-nc/4.0/.

\section{ORCID iDs}

Sascha De Breij http://orcid.org/0000-0002-1970-6041

Daniel Holman http://orcid.org/0000-0003-4134-6238

\section{REFERENCES}

1 Christensen K, Doblhammer G, Rau R, et al. Ageing populations: the challenges ahead. Lancet 2009;374:1196-208.

2 de Wind A, Geuskens GA, Reeuwijk KG, et al. Pathways through which health influences early retirement: a qualitative study. BMC Public Health 2013;13:292.

3 Mortelmans D, Vannieuwenhuyze JTA. The age-dependent influence of self-reported health and job characteristics on retirement. Int J Public Health 2013:58:13-22.

4 Hoven H, Montano D, Siegrist J. Social inequalities, working conditions, and health: evidence from cohort and intervention studies. Eur J Public Health 2013:23.

5 Zajacova A, Montez JK, Herd P. Socioeconomic disparities in health among older adults and the implications for the retirement age debate: a brief report. J Gerontol B Psychol Sci Soc Sci 2014;69:973-8.

6 Kim J, Durden E. Socioeconomic status and age trajectories of health. Soc Sci Med 2007;65:2489-502.

7 Freeman A, Tyrovolas S, Koyanagi A, et al. The role of socio-economic status in depression: results from the courage (aging survey in Europe). BMC Public Health 2016:16:1098

8 Lorant V, Deliège D, Eaton W, et al. Socioeconomic inequalities in depression: a metaanalysis. Am J Epidemiol 2003;157:98-112.

9 Miech RA, Shanahan MJ. Socioeconomic status and depression over the life course. J Health Soc Behav 2000;41:162-76.

10 Olshansky SJ, Antonucci T, Berkman L, et al. Differences in life expectancy due to race and educational differences are widening, and many may not catch up. Health Aff 2012:31:1803-13.

11 van den Berg TIJ, Elders LAM, Burdorf A. Influence of health and work on early retirement. J Occup Environ Med 2010:52:576-83.

12 van Rijn RM, Robroek SJW, Brouwer S, et al. Influence of poor health on exit from paid employment: a systematic review. Occup Environ Med 2014;71:295-301.

13 Rice NE, Lang IA, Henley W, et al. Common health predictors of early retirement: findings from the English longitudinal study of ageing. Age Ageing 2011;40:54-61.

14 Nexo MA, Borg V, Sejbaek CS, et al. Depressive symptoms and early retirement intentions among Danish eldercare workers: cross-sectional and longitudinal analyses. BMC Public Health 2015:15:677.

15 Schuring M, Schram JL, Robroek SJ, et al. The contribution of health to educational inequalities in exit from paid employment in five European regions. Scand J Work Environ Health 2019;45:346-55.

16 Visser M, Gesthuizen M, Kraaykamp G, et al. Inequality among older workers in the Netherlands: a life course and social stratification perspective on early retirement. Eur Sociol Rev 2016;32:370-82.

17 Schuring M, Robroek SJW, Otten FWJ, et al. The effect of ill health and socioeconomic status on labor force exit and re-employment: a prospective study with ten years follow-up in the Netherlands. Scand I Work Environ Health 2013;39:134-43.

18 Lindholm C, Burström B, Diderichsen F. Class differences in the social consequences of illness? J Epidemiol Community Health 2002:56:188-92.

19 van Zon SKR, Reijneveld SA, Mendes de Leon CF, et al. The impact of low education and poor health on unemployment varies by work life stage. Int J Public Health 2017;62:997-1006.

20 Schuring M, Burdorf L, Kunst A, et al. The effects of ill health on entering and maintaining paid employment: evidence in European countries. J Epidemiol Community Health 2007;61:597-604

21 Oude Hengel K, Robroek SJW, Eekhout I, et al. Educational inequalities in the impact of chronic diseases on exit from paid employment among older workers: a 7-year prospective study in the Netherlands. Occup Environ Med 2019;76:718-25.

22 Hämmig O, Bauer GF. The social gradient in work and health: a cross-sectional study exploring the relationship between working conditions and health inequalities. BMC Public Health 2013;13:1170.

23 Carr E, Fleischmann M, Goldberg M, et al. Occupational and educational inequalities in exit from employment at older ages: evidence from seven prospective cohorts. Occup Environ Med 2018;75:369-77.

24 Schieman S, Plickert G. How knowledge is power: education and the sense of control. Social Forces 2008;87:153-83.

25 Robroek SJW, Rongen A, Arts $\mathrm{CH}$, et al. Educational inequalities in exit from paid employment among Dutch workers: the influence of health, lifestyle and work. PLOS One 2015;10:e0134867.

26 Hofer SM, Piccinin AM. Integrative data analysis through coordination of measurement and analysis protocol across independent longitudinal studies. Psychol Methods 2009;14:150-64

27 Hoogendijk EO, Deeg DJH, Poppelaars J, et al. The longitudinal aging study Amsterdam: cohort update 2016 and major findings. Eur J Epidemiol 2016;31:927-45 
28 Lauritzen HH. AEldres ressourcer og behov i perioden 1997-2012. SFI - Det Nationale Forskningscenter for Velfærd, 2014.

29 Steptoe A, Breeze E, Banks J, et al. Cohort profile: the English longitudinal study of ageing. Int J Epidemiol 2013;42:1640-8.

30 Engstler, H, Schmiade, N. The German ageing survey (DEAS) - a longitudinal and timeseries study of people in the second half of life. Schmollers Jahrbuch 2013:133:97-107.

31 Franke H. Monika Bullinger und Inge Kirchberger SF-36. Fragebogen zum Gesundheitszustand. Handanweisung.. Zeitschrift für Medizinische Psychologie 1998;7:190-1.

32 Radloff LS. The CES-D scale: a self-report depression scale for research in the general population. Appl Psychol Meas 1977;1:385-401.
33 Edge CE, Cooper AM, Coffey M. Barriers and facilitators to extended working lives in Europe: a gender focus. Public Health Rev 2017;38:2.

34 Korn EL, Graubard BI, Midthune D. Time-to-event analysis of longitudinal follow-up of a survey: choice of the time-scale. Am J Epidemiol 1997; 145:72-80.

35 OECD. OECD employment outlook 2013. Paris: OECD Publishing, 2013.

36 Schils T. Early retirement in Germany, the Netherlands, and the United Kingdom: a longitudinal analysis of individual factors and institutional regimes. Eur Sociol Rev 2008;24:315-29.

$37 \mathrm{Li} \mathrm{CY}$, Sung FC. A review of the healthy worker effect in occupational epidemiology. Occup Med 1999;49:225-9. 